\title{
Anteseden Niat Membeli Produk Counterfeit
}

\author{
Harini Abrilia Setyawati \\ STIE Putra Bangsa Jl. Ronggowarsito No. 18 Pejagoan, Kebumen \\ Email: harini.abrilia.setyawati@gmail.com
}

\begin{abstract}
This study aims to determine the effect of novelty seeking variables, brand image, materialism on purchase intentions of counterfeit products. The population of this research is the people in Kebumen Regency. The sample in this study were 100 people. The sampling technique used is non-probability sampling. The method of collecting data using a questionnaire. Data analysis used descriptive analysis and statistical analysis. The data processing tool used is SPSS for windows version 25.0. The results of this study indicate that (1) the novelty seeking variable affects the intention to buy counterfeit products. (2) the variable brand image affects the intention to buy counterfeit products. (3) the materialism variable affects the intention to buy counterfeit products.

Keywords: novelty seeking, brand image, materialism counterfeit
\end{abstract}

\section{PENDAHULUAN}

Counterfeit menurut Lai dan Zaichkowsky (1999) adalah produk yang dibuat secara illegal yang menyerupai barang asli tetapi biasanya kualitas lebih rendah. Barang palsu adalah ilegal, harga rendah, dan seringkali berkualitas rendah replika produk yang biasanya memiliki kualitas tinggi nilai merek (Lai dan Zaichkowsky 1999). Pembelian produk palsu telah menjadi masalah global, baik di negara maju maupun berkembang. Pemalsuan mencakup berbagai barang, yang sebagian besar merupakan barang mewah yang biasanya dibeli di pasar gelap (seperti pakaian desainer, perhiasan, jam tangan, dan sepatu), yang sebagian besar dikonsumsi secara mencolok (Martin Eisend, Hartmann, \& Apaolaza, 2017). Literatur sebelumnya menunjukkan beberapa faktor penentu niat membeli barang palsu, seperti; keunggulan

Vol. 12, No. 1, Januari 2021, Halaman 91-99 merek (Purwanto, Margiati, Kuswandi, \& Prasetyo, 2019), etika dan pencarian variasi (Nagar \& Singh, 2019), manfaat ekonomi dan hedonis (Kaufmann, Petrovici, Filho, \& Ayres, 2016), faktor sosial dan kepribadian (Hidayat \& Diwasasri, 2013). Penelitian lainnya, Persepsi Proliferasi Pemalsuan (PCP) (Srisomthavil \& Assarut, 2018).

International Anti-Counterfeiting Coalition (IACC) menyatakan bahwa perdagangan produk palsu mencapai 5-7 persen dari perdagangan dunia. Berdasarkan Perjanjian tentang Aspek Terkait Perdagangan dari Hak Kekayaan Intelektual (Perjanjian WTO), barang palsu adalah semua barang yang mengandung merek dagang yang melanggar dan melanggar hak pemilik merek dagang di bawah hukum negara pengimpor. Istilah pembajakan dan pemalsuan sering digunakan oleh 
masyarakat umum (Marin Eisend \& Schuchert-Güler, 2006).

Masalah ekonomi yang signifikan disebabkan oleh produksi dan penggunaan barang palsu. Para pemalsu memasarkan barang mereka dengan cara yang tidak biasa. Pengemasan dan produk dibuat sangat pintar sehingga label palsu dan asli hampir tidak ada perbedaan. Di bidang fashion dan item pakaian palsu, lebih banyak karena setiap anak muda dan perantara menginginkan sesuatu yang penting untuk dibawa (Abdullaha, Abdul Samad, Hassan, \& Arab, 2017). Penelitian ini meneliti faktor yang mempengaruh minat beli konsumen terhadap produk palsu, yaitu novelty seeking, brand image, social influence dan materialism.

\section{Niat Membeli Produk Counterfeit}

Beberapa faktor, yang mempengaruhi niat untuk membeli produk palsu yang diklasifikasikan ke dalam empat kategori: orang, produk, konteks sosial dan budaya, dan situasi pembelian, telah diusulkan untuk mempengaruhi sikap konsumen terhadap pembelian barang palsu (Marin Eisend \& Schuchert-Güler, 2006). Niat adalah gejala kesiapan seseorang untuk melakukan perilaku tertentu, dan dianggap sebagai anteseden langsung dari perilaku (Cheng, $\mathrm{Fu}, \& \mathrm{Tu}, 2011)$. Niat membeli diartikan sebagai keinginan konsumen untuk membeli (Inkon, 2013).

\section{Hubungan Novelty Seeking dan Niat Membeli Produk Counterfeit}

Novelty Seeking memiliki hubungan positif terhadap niat membeli barang palsu, yang menunjukkan bahwa niat untuk membeli

Vol. 12, No. 1, Januari 2021, Halaman 91-99 produk palsu dibentuk oleh orang yang mencari untuk item baru. Pencarian novel secara positif mempengaruhi penilaian barang ilegal oleh pelanggan (Abid \& Abbasi, 2014). Sebuah studi yang dilakukan di Ghana menemukan bahwa pencarian inovasi, persepsi harga, reputasi dan konsumsi prestise merupakan faktor kunci yang mempengaruhi sikap konsumen terhadap pembelian produk tekstil palsu (Ghartey \& Mensah, 2015).

H1: Novelty Seeking berpengaruh positif terhadap niat membeli produk Counterfeit.

\section{Hubungan Brand Image dan Niat Membeli Produk Counterfeit}

Pada umumnya konsumen yang memiliki preferensi dengan kemewahan asli tertentu barang mencari merek atau prestise. Sedangkan barang mewah palsu bukanlah barang asli dengan merek dagang barang mewah asli, yang memberikan fungsi yang sama dengan barang mewah aslinya, bahkan menunjukkan image merek produk asli karena berperan peran penting dalam mempengaruhi pilihan konsumen (Dickson et al., 2000).

Citra merek terutama memberikan manfaat ekspresi diri. Sebagai merek yang bertujuan untuk meningkatkan citra penggunanya, merek itu sendiri yang dimilikinya kemampuan untuk memuaskan kebutuhan konsumen. Konsumen produk palsu tidak mencari orisinalitas tetapi hanya ingin membeli produk karena citra mereknya. Citra merek juga dapat mempengaruhi perilaku konsumen terhadap pembelian di 
masa mendatang (Chiu \& Leng, 2015; Bian et al., 2016; Hardjono \& San, 2017).

Studi terbaru menunjukkan bahwa jika barang memiliki Citra yang lebih baik, mendorong kemauan konsumen untuk membeli barang palsu (Nguyen et al., 2013), sejalan dengan temuan Gani et al. (2019) menemukan bahwa citra merek merupakan salah satu atribut yang mempengaruhi perilaku niat. Penelitian ini mengasumsikan bahwa semakin tinggi citra merek barang asli maka semakin tinggi pula niat beli terhadap barang mewah palsu tersebut.

H2: Citra merek barang asli berpengaruh positif terhadap niat membeli produk Counterfeit.

\section{Hubungan Materialisme dan Niat Membeli Produk Counterfeit}

Belk (1985) mengasumsikan bahwa materialisme terdiri dari tiga karakteristik: posesif, nongenerositas, dan kecemburuan, sedangkan materialisme dicirikan oleh (Richins \& Dawson, 1992) sebagai sentralitas perolehan, perolehan sebagai pencapaian kesenangan, dan pencapaian yang ditentukan oleh kepemilikan. Banyak orang yang berperingkat tinggi dalam skala kebahagiaan menganggap bahwa kepemilikan dan pembelian penting untuk kepuasan dan kesejahteraan hidup mereka. Ukuran pencapaian mewakili sejauh mana individu tampaknya mengukur diri mereka sendiri dan orang lain dengan jumlah dan kualitas aset yang diperoleh. Materialisme memang memperhitungkan variasi dalam kemampuan orang untuk mengonsumsi produk palsu (Furnham \& Valgeirsson,

Vol. 12, No. 1, Januari 2021, Halaman 91-99
2007). Berbagai tindakan pencarian keragaman dan materialisme pelanggan memiliki dampak menguntungkan pada niat membeli barang palsu non-tipuan oleh pelanggan (Nagar \& Singh, 2019). Keyakinan dalam materialisme menyalahkan variasi dalam kemampuan orang untuk menerima produk palsu (Furnham \& Valgeirsson, 2007).

H3: Materialisme berpengaruh positif terhadap niat membeli produk Counterfeit.

\section{Metodologi}

Populasi penelitian ini adalah masyarakat di Kabupaten Kebumen. Penelitian ini menggunakan sampel minimal yaitu sebanyak 100 responden (Hair et. Al, 2009). Teknik pengambilan sampel yang digunakan adalah pusposive sampling, dengan kriteria orang yang mengetahui emngenai produk counterfeit. Data menggunakan data primer yang dikumpulkan melalui survey dengan kuesioner, melalui Google form. Data diolah menggunakan SPSS 25.

\section{Hasil}

\section{Uji Validitas Dan Reliabilitas}

Suatu instrumen dikatakan valid, apabila pertanyaan yang diajukan pada kuisioner tersebut mampu mengungkap suatu yang diukur oleh kuisioner tersebut. Dalam penelitian ini menggunakan tabel $r$ dengan uji significance level dengan $\mathrm{df}=\mathrm{n}$ $-\mathrm{k}(\mathrm{df}=100-2=98)$ dengan tingkat signifikansi 95\%, maka dipperoleh angka $\mathrm{r}$ tabel sebesar 0,196 dari 100 responden. Hasil Uji Validitas seluruh pertanyaan yang 
digunakan dalam kuesioner dinyatakan

valid.

Tabel 1. Hasil Uji Reliabilitas

Variabel
Novelty Seeking
Brand Image
Materialism
Niat Membeli Produk Counterfeit
Berdasarkan Tabel di atas dapat
ijelaskan bahwa seluruh variabel yang
igunakan dalam penelitian ini dinyatakan
eliabel (andal) dikarenakan nilai alpha
ebih besar dari nilai cronbranch alpha
ebesar 0,60.

Uji Multikolinearitas

Tabel 2. Multikolinearitas

0,695Uji HeteroskedGstisitas Reliabel

0,655 Gambar 10,60ji HeteroskRdtirstbeitas

diketahui hahwa model regresi ini_tidak 0,687 0,60 Reliabel terdapat multikolinieritas, sehingga model

0,865regresi dapat difakai. Reliabel

dijelaskan bahwa seluruh variabel yang digunakan dalam penelitian ini dinyatakan reliabel (andal) dikarenakan nilai alpha lebih besar dari nilai cronbranch alpha sebesar 0,60.

\begin{tabular}{lll}
\hline \multicolumn{1}{c}{ Variabel } & Tolerance & VIF \\
\hline Novelty Seeking & 0.984 & 1.016 \\
Brand Image & 0.998 & 1.002 \\
Materialism & 0.985 & 1.015
\end{tabular}

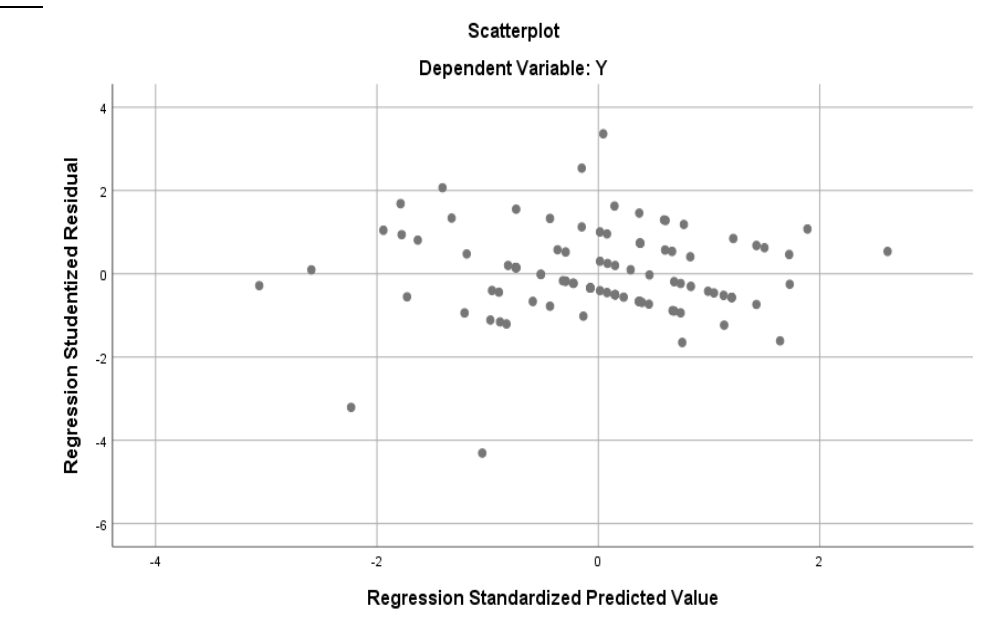

Berdasarkan Tabel di atas dapat

Berdasarkan Gambar heterokedastisitas di atas menunjukan bahwa tidak ada pola tertentu, seperti titik titik (poin) yang membentuk suatu pola tertentu yang teratur (bergelombang, melebar, kemudian menyempit) dan tidak ada pola yang jelas, maka dapat disimpulkan model regresi dalam penelitian ini tidak terjadi heterokedastisitas.

dijelaskan bahwa tabel coefficients di atas dpat dijelaskan bahwa pada bagian Collinearity Statistics menunjukan angka

Vol. 12, No. 1, Januari 2021, Halaman 91-99 


\section{Uji Normalitas}

Gambar 2. Uji Normalitas

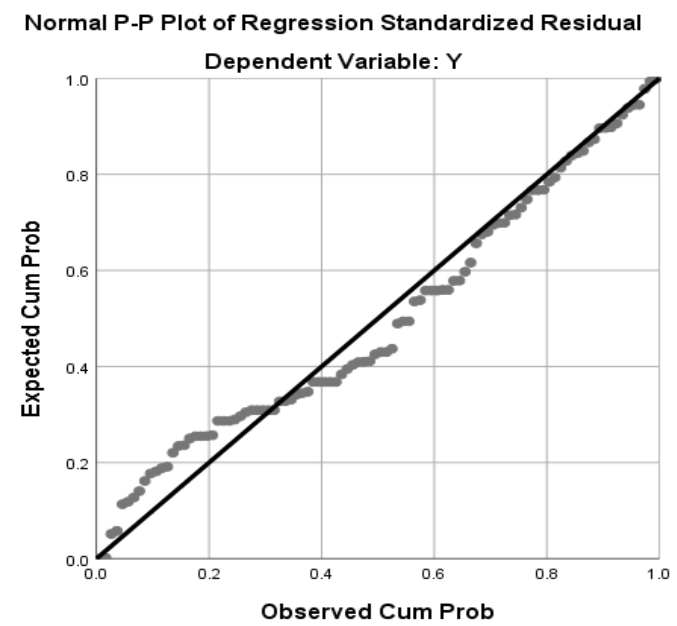

Berdasarkan Gambar 2 di atas menunjukan bahwa data menyebar disekitar garis diagonal dan mengikuti arah garis diagonal, maka dapat disimpulkan model regresi tersebut memenuhi asumsi normalitas.

\section{Analisis Regresi Linear Berganda}

Tabel 3. Hasil Uji t

$$
\text { Variabel }
$$

$\mathrm{t}$

Sig.

Hipotesis

\begin{tabular}{lcccc}
\hline Novelty Seeking -> Niat Membeli Produk Counterfeit & 3.752 & 0.000 & Diterima \\
Brand Image -> Niat Membeli Produk Counterfeit & 4.347 & 0.000 & Diterima \\
Materialism -> Niat Membeli Produk Counterfeit & 4.048 & 0.000 & Diterima \\
\hline
\end{tabular}


1. Pengaruh Novelty Seeking terhadap Niat Membeli Produk Counterfeit Berdasarkan hasil analisis di atas variabel Novelty Seeking (X1) memiliki t hitung sebesar $3.752>\mathrm{t}$ tabel sebesar 1,984 dengan tingkat signifikan $0,000<0,05$. Hal ini menyatakan bahwa variabel Novelty Seeking mempunyai pengaruh yang signifikan terhadap Niat Membeli Produk Counterfeit.

2. Pengaruh Brand Image terhadap Niat Membeli Produk Counterfeit Berdasarkan hasil analisis di atas variabel Brand Image (X2) memiliki t hitung sebesar $4.347>\mathrm{t}$ tabel sebesar 1,984 dengan tingkat signifikan $0,000<0,05$. Hal ini menyatakan bahwa variabel Brand Image mempunyai pengaruh yang signifikan terhadap Niat Membeli Produk Counterfeit

3. Pengaruh Materialism terhadap Niat Membeli Produk Counterfeit Berdasarkan hasil analisis di atas variabel Materialism (X3) memiliki t hitung sebesar $4.048>\mathrm{t}$ tabel sebesar 1,984 dengan tingkat signifikan $0,000<0,05$. Hal ini menyatakan bahwa variabel Materialism mempunyai pengaruh yang signifikan terhadap Niat Membeli Produk Counterfeit

\section{Uji Koefisien Determinasi (R2)}

Tabel 4.Hasil Uji Koefisien Determinasi (R2)

\begin{tabular}{|c|c|c|c|c|}
\hline \multicolumn{5}{|c|}{ Model Summaryb } \\
\hline Model & $\mathrm{R}$ & & $\begin{array}{l}\text { Adjusted R } \\
\text { Square }\end{array}$ & $\begin{array}{l}\text { Std. Error of } \\
\text { the Estimate }\end{array}$ \\
\hline 1 & $.591^{\mathrm{a}}$ & .349 & .329 & 1.437 \\
\hline \multicolumn{5}{|c|}{ a. Predictors: (Constant), X3, X2, X1 } \\
\hline \multicolumn{5}{|c|}{ b. Dependent Variable: Y } \\
\hline \multicolumn{5}{|c|}{ Berdasarkan Tabel di atas pada kolom } \\
\hline \multicolumn{5}{|c|}{$\begin{array}{l}\text { Adjusted R Square (R2) diperoleh nilai } \\
\text { sebesar 0,329 atau 32,9\%. hal ini berarti } \\
\text { kontribusi variabel novelty seeking, brand } \\
\text { image, materialism Niat Membeli Produk } \\
\text { Counterfeit sebesar 32,9\%. Sedangkan } \\
\text { sisanya dipengaruhi oleh variabel lain yang } \\
\text { tidak diteliti dalam penelitian ini. }\end{array}$} \\
\hline
\end{tabular}

Kesimpulan

1. Berdasarkan hasil analisis menunjukan bahwa variabel novelty seeking mempunyai pengaruh yang signifikan terhadap Niat Membeli Produk Counterfeit.

2. Berdasarkan hasil analisis menunjukan bahwa variabel brand image mempunyai pengaruh yang signifikan terhadap Niat Membeli Produk Counterfeit.

3. Berdasarkan hasil analisis menunjukan bahwa variabel materialism mempunyai pengaruh yang signifikan terhadap Niat Membeli Produk Counterfeit.

\section{REFERENCES}

Abdullaha, W. A. H. W., Abdul Samad, M. H., Hassan, A. S., \& Arab, Y. (2017). International Transaction Journal of Engineering, Management, \& Applied Sciences \& Technologies. International Transaction Journal of 
Engineering, Management, \& Applied

Sciences \& Technologies, 8(3), 169181.

https://doi.org/10.14456/ITJEMAST.2 020.3

Abid, M., \& Abbasi, M. (2014). Antecedents and outcomes of consumer buying attitude; the case of Pakistani counterfeit market. Indian J. Sci. Res, 8(1), 165-176.

Belk, R. W. (1997). Third world consumer culture. Frontier Issues in Economic Thought, 2, 311-313.

Bian, X., \& Moutinho, L. (2009). An investigation of determinants of counterfeit purchase consideration. Journal of Business Research, 62(3), 368-378.

Chaudhry, P. E., \& Stumpf, S. A. (2011). Consumer complicity with counterfeit products. Journal of Consumer Marketing, 28(2), 139-151. https://doi.org/10.1108/073637611111 15980

Cheng, S.-I., Fu, H.-H., \& Tu, L. (2011). Examining customer purchase intentions for counterfeit products based on a modified theory of planned behavior. International Journal of Humanities and Social Science, 1(10), 278-284.

Chuchinprakarn, S. (2003). Consumption of counterfeit goods in Thailand: who are the patrons? ACR European Advances.

Cleveland, M., Laroche, M., \&

Vol. 12, No. 1, Januari 2021, Halaman 91-99
Papadopoulos, N. (2009). Cosmopolitanism, consumer ethnocentrism, and materialism: An eight-country study of antecedents and outcomes. Journal of International Marketing, 17(1), 116-146.

Eisend, Marin, \& Schuchert-Güler, P. (2006). Explaining counterfeit purchases: A review and preview. Academy of Marketing Science Review, 2006(12), 1.

Eisend, Martin, Hartmann, P., \& Apaolaza, V. (2017). Who buys counterfeit luxury brands? A meta-analytic synthesis of consumers in developing and developed markets. Journal of International Marketing, 25(4), 89111.

https://doi.org/10.1509/jim.16.0133

Furnham, A., \& Valgeirsson, H. (2007). The effect of life values and materialism on buying counterfeit products. Journal of Socio-Economics, 36(5), 677-685. https://doi.org/10.1016/j.socec.2007.0 1.004

Gentry, J. W., Putrevu, S., \& Shultz, C. J. (2006). The effects of counterfeiting on consumer search. Journal of Consumer Behaviour: An International Research Review, 5(3), 245-256.

Ghartey, A., \& Mensah, F. B. (2015). Ghanaian Consumers' Attitude towards the Purchase of Counterfeit Textile Products: A Case Study of Cape Coast Metropolis. Journal of 
Business and Enterprise Development, $5,18-35$.

Graham, J. F. (1999). Materialism and consumer behavior: Toward a clearer understanding. Journal of Social Behavior and Personality, 14(2), 241.

Haseeb, A., \& Mukhtar, A. (2016). Antecedents of Consumer' s Purchase Intention of Counterfeit Luxury Product. Journal of Marketing and Consumer Research, 28(1), 15-25.

Hidayat, A., \& Diwasasri, A. H. A. (2013). Factors Influencing Attitudes and Intention to Purchase Counterfeit Luxury Brands among Indonesian Consumers. International Journal of Marketing Studies, 5(4), 143-151. https://doi.org/10.5539/ijms.v5n4p143

Hirschman, E. C. (1980). Innovativeness, novelty seeking, and consumer creativity. Journal of Consumer Research, 7(3), 283-295.

Inkon, K. (2013). A study on luxuries possession desires and purchase intention: A comparative study between luxuries and imitations. Academy of Entrepreneurship Journal, 19(3), 63.

Kaufmann, H. R., Petrovici, D. A., Filho, C. G., \& Ayres, A. (2016). Identifying moderators of brand attachment for driving customer purchase intention of original vs counterfeits of luxury brands. Journal of Business Research, 69(12), 5735-5747. https://doi.org/10.1016/j.jbusres.2016.
05.003

Kozar, J. M., \& Marcketti, S. B. (2011). Examining ethics and materialism with purchase of counterfeits. Social Responsibility Journal, 7(3), 393-404. https://doi.org/10.1108/174711111111 54536

Nagar, K., \& Singh, V. P. (2019). Modelling the Effects of Materialism, Ethics and Variety-Seeking Behaviour on Counterfeit Consumption of Young Consumers. Global Business Review, $1-14$.

https://doi.org/10.1177/097215091881 8015

Newell, S. (2013). Brands as masks: Public secrecy and the counterfeit in Côte d'Ivoire. Journal of the Royal Anthropological Institute, 19(1), 138154. https://doi.org/10.1111/14679655.12007

Norum, P. S., \& Cuno, A. (2011). Analysis of the demand for counterfeit goods. Journal of Fashion Marketing and Management, 15(1), 27-40. https://doi.org/10.1108/136120211111 12322

Patiro, S. P. S., \& Sihombing, S. O. (2014). Predicting Intention to Purchase Counterfeit Products: Extending the Theory of Planned Behavior. International Research Journal of Business Studies, 7(2), 109-120. https://doi.org/10.21632/irjbs.7.2.109120

Phau, I., Sequeira, M., \& Dix, S. (2009). 
Consumers' willingness to knowingly purchase counterfeit products. Direct Marketing: An International Journal, 3(4), 262-281. https://doi.org/10.1108/175059309110 00865

Phau, I., \& Teah, M. (2009). Devil wears (counterfeit) Prada: A study of antecedents and outcomes of attitudes towards counterfeits of luxury brands. Journal of Consumer Marketing, 26(1), 15-27. https://doi.org/10.1108/073637609109 27019

Purwanto, P., Margiati, L., Kuswandi, K., \& Prasetyo, B. (2019). Consumer motives for purchasing counterfeit luxury products: Behind the status signaling behavior using brand prominence. Business: Theory and Practice, 20, 208-215. https://doi.org/10.3846/btp.2019.20

Richins, M. L., \& Dawson, S. (1992). A consumer values orientation for materialism and its measurement: Scale development and validation. Journal of Consumer Research, 19(3), 303-316.

Riptiono, S., \& Setyawati, H. A. (2019). Does Islamic Religiosity Influence Female Muslim Fashion Trend Purchase Intention? An Extended of Theory of Planned Behavior. Iqtishadia: Jurnal Kajian Ekonomi Dan Bisnis Islam, 12(1), 16-36.

Srisomthavil, N., \& Assarut, N. (2018). The impact of perceived counterfeit luxury brand proliferation on luxury brand values and patronage intention. Market-Trziste, 30(1), 41-60. https://doi.org/10.22598/mt/2018.30.1 .41

Teah, M., Phau, I., \& Huang, Y. (2015). Devil continues to wear "counterfeit" Prada: A tale of two cities. Journal of Consumer Marketing. 